\title{
Application of biosynthesized nano-catalyst for biodiesel synthesis and impact assessment of factors influencing the yield
}

\author{
C. P. Gandhi ${ }^{1}$, Rajni Garg ${ }^{2}$, Nnabuk Okon Eddy ${ }^{3}$ \\ ${ }^{1}$ Department of Mathematics, Rayat Bahra University, Mohali, Punjab, 140301, India \\ ${ }^{2}$ Department of Chemistry, Rayat Bahra University, Mohali, Punjab, 140301, India \\ ${ }^{3}$ Department of Pure and Industrial Chemistry, University of Nigeria, Nsukka, Enugu State, 410001, Nigeria \\ cchanderr@gmail.com,rajnigarg@science.org.in,okon.nnabuk@unn.edu.ng
}

DOI 10.17586/2220-8054-2021-12-6-808-817

\begin{abstract}
This study presents a green process to synthesize biodiesel using biosynthesized nano-catalyst and a novel methodology for analyzing the impact of influencing factors - methanol/oil ratio, the concentration of nano-catalyst, temperature, and time of reactions- on the yield of biodiesel obtained by heterogeneous nano-catalyst-based transesterification reaction. Nano-calcium oxide (nano-CaO) was obtained as a heterogeneous nano-catalyst using waste eggshells. Waste cooking oil was treated with methanol and nano-catalyst at varying methanol: oil ratios (4 - 14:1), nano-catalyst concentration $(0.5-2 \%)$, time of reaction $(3-4.5 \mathrm{hrs})$, and temperature $\left(50-65^{\circ} \mathrm{C}\right)$. The superiority and effectiveness of the proposed transesterification indices were accomplished making use of Deluca and Termini fuzzy entropy weighted indexes to obtain optimal reaction conditions with $95.49 \%$ biodiesel yield.
\end{abstract}

Keywords: nano-catalyst, biodiesel, transesterification, fuzzy entropy, neutrosophic entropy.

Received: 17 September 2021

\section{Introduction}

Worldwide consumption of energy is progressing especially in the transportation sector which is solely dependent upon petroleum-based non-renewable resources of energy [1]. These resources are the primary source of increasing environmental pollution due to the emission of carbon dioxide from vehicular exhausts in addition to the greenhouse effect [2]. The resulting environmental degradation and the expected energy depletion require the continuous search for alternative energy resources if the quality of the environment must be maintained [3]. Consideration of the energy policy review indicates that India and several nations of the world are facing great challenges towards alternative and sustainable energy resources that are eco-friendly, less expensive, biodegradable, and easily available [4]. Consequently, the search for biofuels such as biogas, hydrogen cells, and biodiesel has attracted intense research interest because of the potential of green chemistry usage [5]. Biodiesel has emerged as a sulfur-free, bio-degradable, costeffective, non-toxic, and more reliable option among the alternative sustainable fuels [6]. It is miscible in diesel at all proportions and is favored as a blending constituent of automotive fuel due to its very high cetane value and high lubricity [7]. It can be obtained as fatty acid alkyl esters employing transesterification of cheap resources viz oils and fat with alcohols (ethanol/methanol) or alkoxides and homogeneous or heterogeneous catalyst with the production of glycerol as a by-product [8]. Vegetable oil is commonly obtained from oil crops such as coconut, sunflower, canola, palm, mustard, soybean, flax, rapeseed, jatropha, hemp, and rice bran, etc. India has a great potential for production of biodiesel with vast production of oil crops in the wasteland and forest area. In the global society, efforts are ongoing toward reducing dependency on fossil fuels and reducing production costs for biodiesel by opting for low-cost and easy to obtain feedstock and catalysts [9]. Many researchers have used vegetable oils in the form of raw, nonedible and waste oils obtained from various oil processing units as well as from household and locally available food ventures [10].

It has been found that heterogeneous catalysts exhibit better performance compared to homogeneous catalysts. The major factor includes the high production cost during industrial production on large scale due to the involvement of the multistep purification process and difficulties to remove the byproducts such as glycerol formed during the reaction. Treatment of the effluent resulted from this process also adds to the cost [11]. Further, all the conventional feedstock including non-edible oils with high content of fatty acids can not be used in the homogeneous esterification due to the possibility of soap formation that leads to loss of yield and adds to the separation issue of byproducts. Hence, researchers are seeking economically viable and alternative methods for the production of biodiesel [12]. However, the greatest advantage of heterogeneous catalysts is the ease of separation while the disadvantage is limited activity and selectivity. Heterogeneous (solid) catalyst-based transesterification offers future hope to current challenges because solid catalysts are required in a lesser amount compared to conventional catalysts and can be easily separated and be reused. Also, the solid catalyst can be fabricated and tailored as per the requirement to increase the catalytic properties. 
Various solid catalysts including metal oxide and alumina/silica supported metal oxide catalysts have been explored by researchers [13]. Several reports are available with usage of $\mathrm{CaO}$ as a heterogeneous nano-catalyst. Animal eggshells are a rich source of calcium carbonate that can be easily converted to nano-CaO. Throughout the world, eggshells of chicken, duck, and snails are discarded as waste and their improper disposal leads to environmental pollution that results in various health hazards. Hence, the use of waste eggshells for the generation of nano- $\mathrm{CaO}$ as a heterogeneous nano-catalyst is an eco-friendly step [14]. Likewise, edible oil is processed in various food processing units especially in the kitchen and restaurants for frying purposes. After frying, edible oil becomes unfit for consumption and is discarded and is known as waste cooking oil (WCO). This oil is rich in free fatty acids and may be successfully employed to obtain biodiesel using nano- $\mathrm{CaO}$ based heterogeneous transesterification [15].

Production of biodiesel is dependent upon many factors including methanol/oil ratio, temperature, the concentration of nano-catalyst, time of reaction, extent of stirring, etc. [16]. Subsequently, Yi et al. approached the enduring Karl's Pearson's coefficient formula and designed the optimal reaction conditions responsible for transesterification reaction [17]. However, the correlation coefficient formula has some limitations as it can be only used for studying interrelation and thus leads to a non-significant curvilinear relationship between two variables. The fuzzy set theory proposed by Zadeh has been proven as an indispensable tool for optimizing energy-related problems [18]. Ovchinnikov elaborated many impressions of fuzzy sets (FSs), one of which corresponds to the representation of membership degree or grade of the underlying FS [19]. Since then, FSs have been extended into a variety of equivalents and more quantified information is provided by the neutrosophic set (NS) contribute in comparison with the existing fuzzy set theory [20]. Moreover, the NS theory has the potential of predicting optimal reaction conditions under heterogeneous catalyzed transesterification reactions. To handle and solve these problematic issues, an effort is accomplished in this pathway by establishing a novel neutrosophic entropy-based methodology which can play a crucial role for the classification of influencing factors (i) methanol/oil ratio (ii) concentration of nano-catalyst (iii) temperature and (iv) time of reactions, responsible for optimal biodiesel yield, obtained by heterogeneous nano-catalyst-based transesterification reaction. The underlying neutrosophic entropy-based methodology provides remarkable yield information confirming the optimum parameters. The results of this underlying study are superseded as below.

Section 2 provides the details of the materials and procedures employed in performing the reaction. Section 3 introduces the projected methodology for constructing fuzzy entropy weighted waste cooking oil transesterification index (FCOTI), single-valued neutrosophic entropy weighted waste cooking oil transesterification index (SCOTI), and Deluca and Termini fuzzy entropy-based weighted waste cooking oil transesterification index (ECOTI) respectively. Section 4 provides the details for the characterization of the prepared nano-catalyst and biodiesel. It also provides the applicability and remarkability of the underlying methodology by identifying the most influencing reaction set, responsible for the optimum biodiesel yield whereas Section 5 finally summarizes the study. The basic terminology of fuzzy and neutrosophic entropy measures, required for the successive progress of the underlying study has been given in supplementary information.

\section{Materials and methods}

\subsection{Materials}

WCO, procured from the resident food vendors, was utilized as resource material for the reaction. Waste chicken eggshells, collected from the local food junctions, were used to develop the heterogeneous nano-catalyst. All the chemicals of analytical grade were acquired from Merck, Mumbai, and were utilized without any additional processing or purification.

\subsection{Collection of reaction sets}

A heterogeneous nano-catalyst based on waste eggshells was developed by the procedure given in literature [21]. Methanol has been used as a solvent and co-reactant. After washing, drying, and grinding, the eggshells were calcined to obtain nano-CaO as a nano-catalyst. The nano-catalyst was characterized by FTIR (Model Perkin Elmer Spectrum 400 FT-IR Spectrometer) operating with a resolution of $2 \mathrm{~cm}^{-1}\left(\right.$ range $4000-400 \mathrm{~cm}^{-1}$ ) and XRD (Model PANalytical X'Pert Pro) operating at a voltage of $45 \mathrm{kV}$ with a current of $35 \mathrm{~mA}$ using $\mathrm{Cu}-\mathrm{K} \alpha$ radiation $(K=1.5406 \AA)$ and $2 \theta$ ranging from $20-80^{\circ}$ at a continuous speed of $0.045^{\circ}$ per min. Waste cooking oil was subjected to filtration for the removal of any insoluble impurities and was pre-treated with anhydrous sodium sulfate before heating at $100{ }^{\circ} \mathrm{C}$. The reaction was executed in a batch reactor supported with a thermostatic water bath and magnetic stirrer by varying methanol: oil ratio $(4-14: 1)$, nano-catalyst concentration $(0.5-2 \%)$, time of reaction $(3-4.5 \mathrm{hrs}$.), and temperature $\left(50-65^{\circ} \mathrm{C}\right)$ as per reaction sets and a constant stirring was maintained.

After the separation of glycerol, the by-product, the $\%$ yield of biodiesel was determined using the standard equation [22]. The biodiesel so obtained was characterized by FTIR (Model Perkin Elmer Spectrum 400 FT-IR 
Spectrometer) and GC-MS analysis (Model THERMO Scientific Trace 1300GC) operating at conditions as shown in Table 1.

TABLE 1. GC-MS Conditions for the analysis of essential oils

\begin{tabular}{|c|c|c|}
\hline \multicolumn{3}{|c|}{ GC Condition } \\
\hline \multicolumn{2}{|c|}{ Injection Temperature } & $280^{\circ} \mathrm{C}$ \\
\hline \multicolumn{2}{|c|}{ Injection Mode } & Split \\
\hline \multicolumn{2}{|c|}{ Column Flow (Helium) } & $1.21 \mathrm{~mL} / \mathrm{min}$ \\
\hline \multicolumn{2}{|c|}{ Split Ratio } & 5 \\
\hline \multicolumn{2}{|c|}{ Injection Volume } & $1 \mu \mathrm{L}$ \\
\hline \multicolumn{3}{|c|}{ MS Conditions (EI mode at $70 \mathrm{eV}$ ) } \\
\hline \multicolumn{2}{|c|}{ Ion Source Temperature } & $200^{\circ} \mathrm{C}$ \\
\hline \multicolumn{2}{|c|}{ Interface Temperature } & $280^{\circ} \mathrm{C}$ \\
\hline \multicolumn{2}{|c|}{ Solvent Cut Time } & $2.2 \mathrm{~min}$ \\
\hline \multicolumn{2}{|c|}{ Start Time } & $2.5 \mathrm{~min}$ \\
\hline \multicolumn{2}{|c|}{ End Time } & $55 \mathrm{~min}$ \\
\hline \multicolumn{2}{|c|}{ Start $\mathrm{m} / \mathrm{z}$} & 40 \\
\hline \multicolumn{2}{|c|}{ End $\mathrm{m} / \mathrm{z}$} & 700 \\
\hline \multicolumn{3}{|c|}{ Oven Temperature Program } \\
\hline \multirow[t]{2}{*}{ Rate $\left({ }^{\circ} \mathrm{C} / \mathrm{min}\right)$} & Temperature $\left({ }^{\circ} \mathrm{C}\right)$ & Hold Time (min) \\
\hline & 60 & 1 \\
\hline 5 & 220 & 2 \\
\hline 5 & 280 & 8 \\
\hline
\end{tabular}

\section{Normalization of monitored biodiesel yield}

Suppose the number of parameters (influencing factors) under study is denoted by " $n$ ". Let the number of reaction sets to be optimized is denoted by " $m$ ". Let $r_{j i}$ denote the monitored biodiesel yield of the $j^{\text {th }}$ influencing factor at $i^{t h}$ reaction set. To diminish the errors created by the various influencing factor, it becomes essential for us to normalize each monitored biodiesel yield. If $V_{j i}$ denotes the normalization construction function for a typical $j^{t h}$ influencing factor at a particular $i^{\text {th }}$ reaction set, then:

$$
V_{j i}=\frac{r_{j i}-\min r_{j i}}{\max r_{j i}-\min r_{j i}},
$$

where $j$ runs over 1 to $n$ and $i$ over 1 to $m$.

\subsection{Determination of fuzzy and neutrosophic entropy weights}

In the existing literature of Information theory, many fuzzy entropy (FE) measures have been investigated and characterized by researchers, but with some faults and limitations. De Luca and Termini suggested the first nonadditive FE measure as follows [23]:

$$
H_{F}^{d}\left(C_{F S}^{b}\right)=-\frac{1}{\log m} \sum_{j=1}^{n}\left[\tilde{\mu}_{C^{b}}\left(p_{j}\right) \log \tilde{\mu}_{C^{b}}\left(p_{j}\right)+\left(1-\tilde{\mu}_{C^{b}}\left(p_{j}\right)\right) \log \left(1-\tilde{\mu}_{C^{b}}\left(p_{j}\right)\right)\right]
$$

where $m$ is a fixed natural number.

The fuzzy entropy $H_{F}^{d}\left(C_{F S}^{b}\right)$ has been found capable of optimizing the uncertainty problems associated with various aspects of the environment, pollution, and energy-saving resources. Unfortunately, the FE measure is facing a major drawback with assumption $0 \times \log 0=0$. Due to this reason, this fuzzy entropy faced intrinsic conflicts and hence indicated uncertainty and elusiveness in the quality evaluation. To overcome this problematic situation and to meet the exigency, we have been able to establish Neutrosophic fuzzy entropy (NTFE) and applied it for identifying 
the most influencing reaction sets responsible for the optimal bio-diesel yield. Let $T_{j i}$ denote the amount of fuzziness (concentration) based on the truth membership degree of $j^{t h}$ persuading factor at the $i^{\text {th }}$ reaction set. Then:

$$
T_{j i}=\frac{V_{j i}}{\sum_{j=1}^{n} V_{j i}}
$$

where $j$ runs over 1 to $n$ and $i$ over 1 to $m$.

(a) The weights $W_{j i}^{1}$ of $j^{\text {th }}$ influencing factors at $i^{\text {th }}$ reaction set can be determined as follows. Let $m$ be the number of reaction sets, then:

where

$$
W_{j i}^{1}=\frac{1-H_{j i}^{1}}{\sum_{j=1}^{n} H_{j i}^{1}}
$$

where

$$
H_{j i}^{1}=-\frac{1}{\log m} \sum_{j=1}^{n}\left[T_{j i} \log T_{j i}+\left(1-T_{j i}\right) \log \left(1-T_{j i}\right)\right] .
$$

(b) The weights $W_{j i}^{2}$ of $j^{\text {th }}$ influencing factors at $i^{\text {th }}$ reaction set employing the proposed trigonometric FE measure (1) can be determined as follows. Let $m$ be the number of reaction sets, then:

$$
W_{j i}^{2}=\frac{1-H_{j i}^{2}}{\sum_{j=1}^{n} H_{j i}^{2}}
$$

$$
H_{j i}^{2}=-\tan \left(\frac{1}{m}\right) \sum_{j=1}^{n}\left[\tan \left(\frac{2}{\sqrt{2}+\sqrt{T_{j i}}+\sqrt{\left(1-T_{j i}\right)}}\right)-\tan \left(\frac{2}{\sqrt{2}+1}\right)\right] .
$$

(c) Let $F_{j i}=1-V_{j i}$ and $I_{j i}=1-V_{j i}-F_{j i}$ denote the amount of fuzziness (concentration) based on falsity and indeterminacy membership degree of $j^{\text {th }}$ influencing factor at $i^{\text {th }}$ reaction set respectively. Then, the weights $W_{j i}^{(3)}$ of $j^{\text {th }}$ influencing factors at $i^{\text {th }}$ reaction set employing the proposed Single Valued Neutrosophic Entropy (SVNE) measure can be determined as follows. Let $m$ be the number of reaction sets, then:

$$
W_{j i}^{(3)}=\frac{1-H_{j i}^{3}}{\sum_{j=1}^{n} H_{j i}^{3}},
$$

where

$$
\begin{aligned}
H_{j i}^{3}=\tan \left(\frac{1}{m}\right) \sum_{j=1}^{n} & {\left[3 \tan \left(\frac{2}{\sqrt{2}+1}\right)-\tan \left(\frac{2}{\sqrt{2}+\sqrt{I_{j i}}+\sqrt{1-I_{j i}}}\right)\right.} \\
& -\left(\frac{2+V_{j i}+F_{j i}}{3}\right) \tan \left(\frac{1+V_{j i}+F_{j i}}{\sqrt{2}+\left(\sqrt{V_{j i}}+\sqrt{F_{j i}}\right)\left(\sqrt{V_{j i}+F_{j i}}\right)}\right) \\
& \left.-\left(\frac{4-V_{j i}-F_{j i}}{3}\right) \tan \left(\frac{3-V_{j i}-F_{j i}}{\sqrt{2}+\left(\sqrt{1-V_{j i}}+\sqrt{1-F_{j i}}\right)\left(\sqrt{2-V_{j i}-F_{j i}}\right)}\right)\right] .
\end{aligned}
$$

\subsection{Calculation of relative sub-indices of each influencing factor at various reaction sets}

Two types of sub-indices, absolute and relative, are being used by eminent researchers. Since absolute (or relative) sub-indexing approaches are fully independent (or dependent) on quality standards, the relative sub-indexing approach has been empowered in this study.

Let $Q_{j i}=$ The relative sub-indices, $S_{j i}=$ The maximum monitored biodiesel yield, and $c_{j i}=$ The monitored biodiesel yield of the $j^{\text {th }}$ influencing factor at $i^{\text {th }}$ reaction set consecutively. Then, the relative sub-indexing of each influencing factor concerning various reaction sets in this study has been assigned by:

$$
Q_{j i}=\frac{c_{j i}}{S_{j i}} \times 100
$$

where $j$ runs over 1 to $n$ and $i$ over 1 to $m$. 


\subsection{Constructions of ECOTI, FCOTI and SCOTI}

The existing Deluca-Termini fuzzy entropy, proposed fuzzy trigonometric entropy and SVNE weighted waste cooking oil transesterification indices (ECOTI, FCOTI and SCOTI) can be computed employing the following equations:

$$
\begin{aligned}
& \text { ECOTI at } i^{\text {th }} \text { reaction set }=\sum_{j=1}^{n} W_{j i}^{1} Q_{j i}, \\
& \text { FCOTI at } i^{\text {th }} \text { reaction set }=\sum_{j=1}^{n} W_{j i}^{2} Q_{j i}, \\
& \text { SCOTI at } i^{\text {th }} \text { reaction set }=\sum_{j=1}^{n} W_{j i}^{3} Q_{j i} .
\end{aligned}
$$

The maximum ECOTI, FCOTI, or SCOTI score for a typical influencing factor at a particular reaction set is designated as the most influencing reaction set.

\section{Results and discussion}

\subsection{Characterization of nano-catalyst}

The X-ray diffraction patterns of nano- $\mathrm{CaO}$ have been plotted in Fig. 1. The narrow and intense peaks in the patterns can be attributed to the crystalline nature (calcite) of nano-CaO [24]. The diffraction patterns clearly show that the nano-catalyst showed characteristic peaks for $\mathrm{CaO}$ at $2 \theta$ equal to $31.5,37.5,46.4,51.1,52.3,55.2$, and 58.1 ${ }^{\circ}$ [25]. The prepared nano-catalyst was also characterized using FTIR analysis as shown in Fig. 2 . A band at $3267.67 \mathrm{~cm}^{-1}$ corresponded to the $\mathrm{O}-\mathrm{H}$ stretching while two bands around 1439.41 and $438.43 \mathrm{~cm}^{-1}$ were attributed to $\mathrm{Ca}-\mathrm{O}$ bending [26]. The FTIR features shown by the nano-catalyst in our study are consistent with the already reported data in the literature [27].

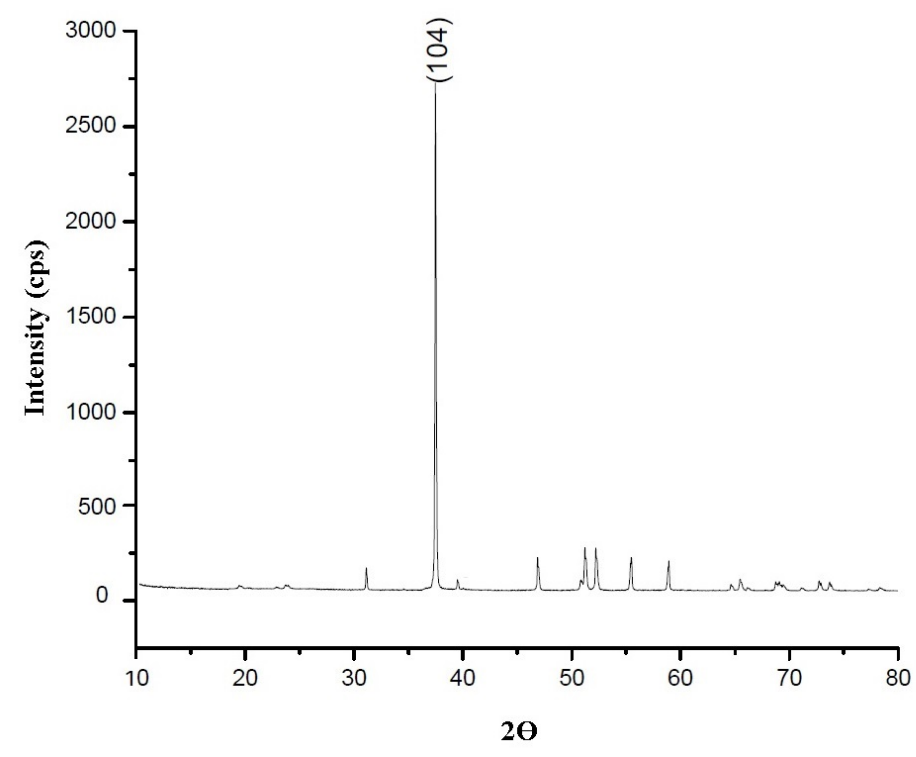

FIG. 1. X-ray Diffraction pattern for nano-CaO

\subsection{Characterization of biodiesel}

The biodiesel composition in terms of fatty acid methyl esters was identified by a pattern of mass fragmentation and the retention time of GCMS analysis. Fig. 3 shows the composition of the biodiesel produced under optimized conditions and confirms the completion of the transesterification reaction. The results found were consistent with previously reported results [28]. 


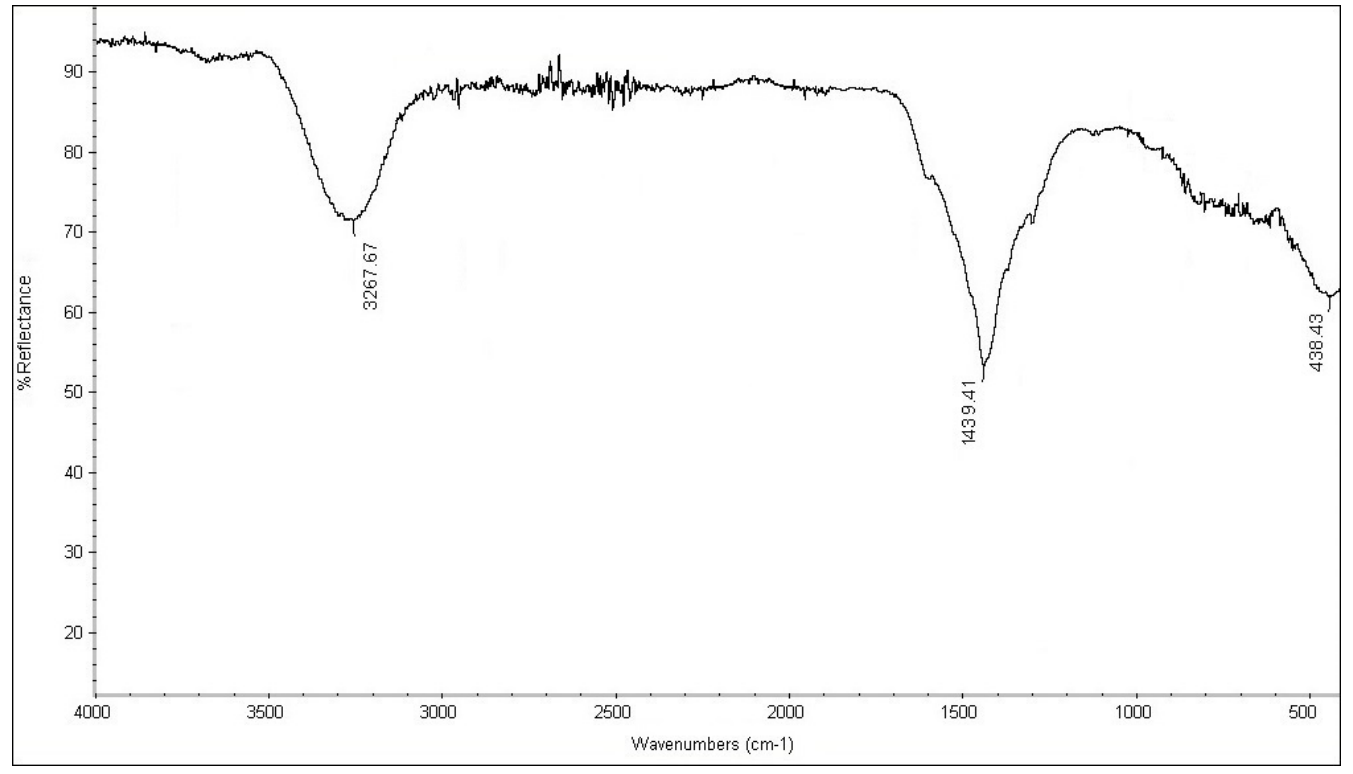

FIG. 2. FTIR spectrum for nano-CaO

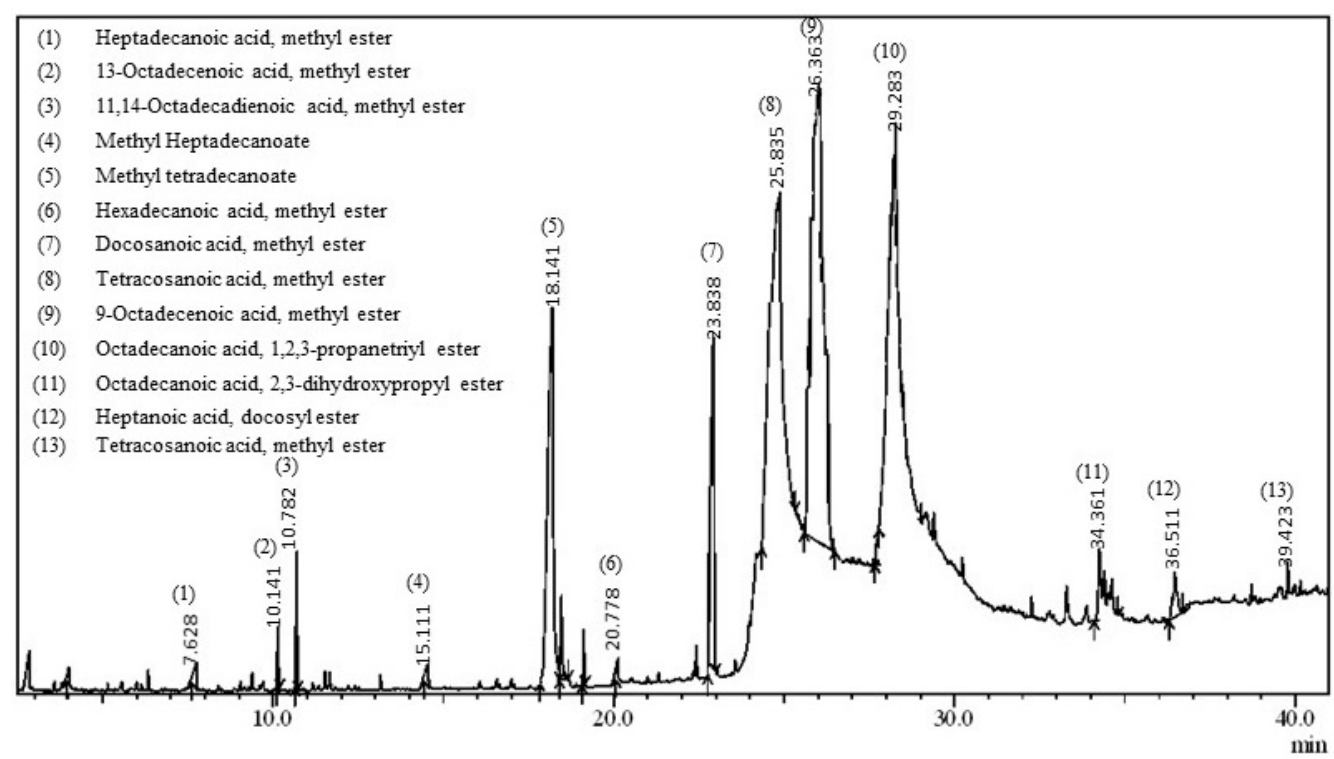

FIG. 3. GCMS for biodiesel

Functional group analysis of biodiesel was explored by FTIR as represented in Fig. 4. The most intense peak at $1755.96 \mathrm{~cm}^{-1}$ was assigned to CO stretching in esters [29,30]. The absorption bands corresponding to the asymmetric bending of methyl groups of esters in the biodiesel were observed at $1639.41 \mathrm{~cm}^{-1}$ while that for stretching vibrations of methoxy groups were observed at $1239.85 \mathrm{~cm}^{-1}[31,32]$. The axial deformation of $\mathrm{CH}_{2}$ bond was indicated by absorption bands at $2911.66 \mathrm{~cm}^{-1}$ [28,33]. The absorption band at 2407.14 , and $2170.60 \mathrm{~cm}^{-1} \mathrm{corre}^{-}$ sponded to stretching vibrations of $\mathrm{C}-\mathrm{O}$ while $\mathrm{O}-\mathrm{H}$ stretching vibration was observed as a weak absorption band at $3400.91 \mathrm{~cm}^{-1}$ [34]. The absorption bands at $628.59 \mathrm{~cm}^{-1}$ corresponded to $\mathrm{CH}_{2}$ and $\mathrm{CH}_{3}$ bending vibrations [28].

\subsection{Identification of most influencing reaction set through ECOTI, FCOTI, and SCOTI}

To predict the most influencing reaction set responsible for the optimum bio-diesel yield employing the proposed methodology has already been explained. The number of influencing factors in this study is four $(n=4)$ and the number of transesterification reaction sets is eleven $(m=11)$ for the concentration of nano-catalyst, temperature, and time of reaction, and ten $(m=10)$ for methanol/oil ratio. We have been able to evaluate Deluca and Termini [23] fuzzy 


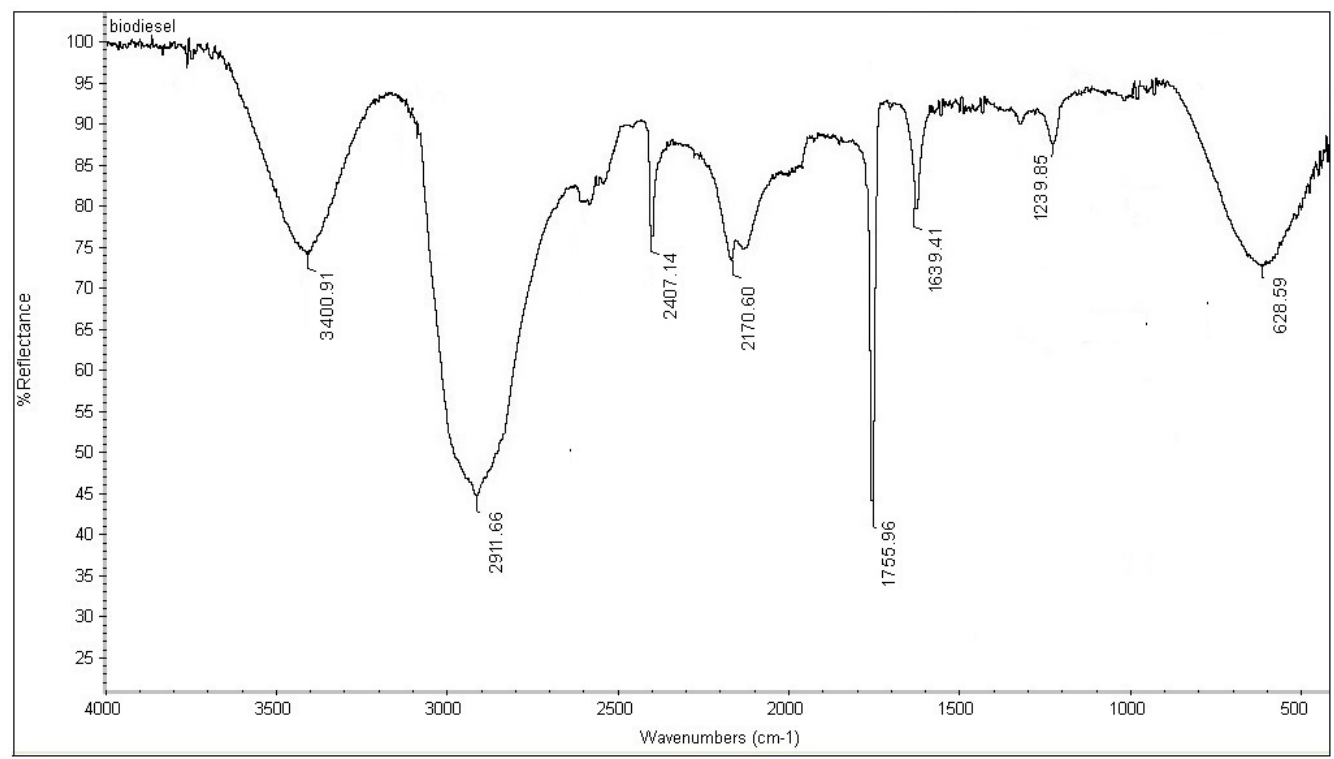

FIG. 4. FTIR spectrum for biodiesel

entropy-based weighted waste cooking oil transesterification index (ECOTI) employing equation (11) concerning each influencing factor at various reaction sets as summarized in Table 2. A careful analysis of the results depicted in Table 2 along with Fig. 5(a) reveals that, like the proposed fuzzy and SVNE measures, for the variation of (i) concentration of nano-catalyst (ii) temperature (iii) time of reaction and (iv) methanol:oil ratio, the reaction sets $R S_{8}, R S_{19}, R S_{30}$, $R S_{35}$ were found to be the most influencing ones owing to their maximum ECOTI scores. The desired TFE weighted waste cooking oil transesterification index (FCOTI) can be evaluated employing equation (12). The results have been depicted in Table 2 along with Fig. 5(b), revealing that for the variation of concentration of nano-catalyst, temperature, time of reaction, and methanol: oil ratio, the reaction sets $R S_{8}, R S_{19}, R S_{30}, R S_{35}$ were found to be the most promising ones owing to their maximum FCOTI scores. Following the proposed methodology and resulting equation (13), the desired trigonometric SVNE weighted waste cooking oil transesterification index (SCOTI) concerning each influencing factor at various reaction sets is summarized in Table 2. The subsequent analysis of the results depicted in Table 2 along with Fig. 5(c) reveals that for the variation of concentration of nano-catalyst, temperature, time of reaction, and methanol: oil ratio, the reaction sets $R S_{8}, R S_{19}, R S_{30}, R S_{35}$ were found to be the most influencing ones owing to their maximum ECOTI scores.

The previous discussion reveals that for the variation in methanol: oil ratio with variation in concentration of nanocatalyst from $0.5-2 \%$, the reaction set $R S_{8}$ was found to be most influencing, owing to its maximum ECOTI, FCOTI, and SCOTI scores. Similarly, for the variation in methanol: oil ratio with variation in temperature of transesterification from $50-65^{\circ} \mathrm{C}$, the reaction set $R S_{19}$ was found to be most effective owing to its maximum ECOTI, FCOTI, and SCOTI scores. Also, for the variation in methanol: oil ratio with variation in time of esterification from $3-4.5$ hrs., the reaction set $R S_{30}$ was found to be most effective owing to its maximum ECOTI, FCOTI, and SCOTI scores. These reaction sets involve the use of methanol: oil ratio as 11:1 which means that the optimized methanol: oil ratio for best yield of biodiesel is 11:1.

During the study of the effect of nano-catalyst concentration, temperature, and time of reactions at constant methanol: oil ratio, it was observed that the reaction set corresponding to the nano-catalyst concentration as $1 \%$, reaction temperature as $60{ }^{\circ} \mathrm{C}$, and reaction time as $4.5 \mathrm{hrs}$., was found to be most effective, owing to its maximum ECOTI, FCOTI, and SCOTI scores resulting in $95.49 \%$ biodiesel yield. It is therefore concluded that during the optimization analysis, the methanol: oil ratio has been the most influencing factor. This is due to the reason that for transesterification reaction, excess methanol is required for obtaining maximum yield (methanol being the co-reactant for the reaction). For a particular methanol: oil ratio, the temperature is the most influencing factor followed by nano-catalyst concentration and time of reaction owing to their highest ECOTI, FCOTI, and SCOTI scores. However, for the optimized value of nano-catalyst concentration and time of reaction, a slight decrease of reaction temperature $55{ }^{\circ} \mathrm{C}$ was observed followed by an increase of reaction temperature $65{ }^{\circ} \mathrm{C}$ indicating that at the optimized value of nano-catalyst concentration and reaction time, temperature change can be afforded. However, all four factors are interdependent and can be suitably varied at particular methanol: oil ratios to obtain the best yield of biodiesel. 
TABLE 2. FCOTI, SCOTI and ECOTI Score for (i) Methanol: Oil Ratio (MR) with the variation of nano-catalyst (Cat), temperature (Temp.) and time of reactions

\begin{tabular}{|c|c|c|c|c|c|c|c|}
\hline \multicolumn{8}{|c|}{ FCOTI Score } \\
\hline$R S s$ & Nano-catalyst & $R S s$ & Temp. & $R S s$ & Time & $R S s$ & MR \\
\hline$R S_{1}$ & 0.0000 & $R S_{12}$ & 0.0000 & $R S_{23}$ & 0.0000 & $R S_{34}$ & 357.83 \\
\hline$R S_{2}$ & 305.80 & $R S_{13}$ & 307.83 & $R S_{24}$ & 294.78 & $R S_{35}$ & 367.57 \\
\hline$R S_{3}$ & 312.72 & $R S_{14}$ & 316.63 & $R S_{25}$ & 302.84 & $R S_{36}$ & 361.33 \\
\hline$R S_{4}$ & 320.19 & $R S_{15}$ & 324.50 & $R S_{26}$ & 310.46 & $R S_{37}$ & 360.21 \\
\hline$R S_{5}$ & 327.81 & $R S_{16}$ & 331.51 & $R S_{27}$ & 316.71 & $R S_{38}$ & 357.39 \\
\hline$R S_{6}$ & 342.00 & $R S_{17}$ & 343.71 & $R S_{28}$ & 330.05 & $R S_{39}$ & 364.27 \\
\hline$R S_{7}$ & 350.00 & $R S_{18}$ & 350.09 & $R S_{29}$ & 337.19 & $R S_{40}$ & 364.15 \\
\hline$R S_{8}$ & 359.44 & $R S_{19}$ & 359.58 & $R S_{30}$ & 347.12 & $R S_{41}$ & 0.0000 \\
\hline$R S_{9}$ & 356.95 & $R S_{20}$ & 358.13 & $R S_{31}$ & 345.09 & $R S_{42}$ & 347.07 \\
\hline$R S_{10}$ & 354.30 & $R S_{21}$ & 356.35 & $R S_{32}$ & 341.65 & $R S_{43}$ & 359.97 \\
\hline$R S_{11}$ & 352.80 & $R S_{22}$ & 354.67 & $R S_{33}$ & 339.19 & & \\
\hline \multicolumn{8}{|c|}{ SCOTI Score } \\
\hline$R S s$ & no-cataly & $R S s$ & Temp. & $R S s$ & Time & $R S s$ & MR \\
\hline$R S_{1}$ & 0 & $R S_{12}$ & 0 & $R S_{23}$ & 0 & $R S_{34}$ & 358.73 \\
\hline$R S_{2}$ & 305.8 & $R S_{13}$ & 307.82 & $R S_{24}$ & 94.78 & $R S_{35}$ & 367.57 \\
\hline$R S_{3}$ & 312.73 & $R S_{14}$ & 316.63 & $R S_{25}$ & 302.84 & $R S_{36}$ & 362.71 \\
\hline$R S_{4}$ & 320.21 & $R S_{15}$ & 324.5 & $R S_{26}$ & 310.47 & $R S_{37}$ & 360.64 \\
\hline$R S_{5}$ & 327.83 & $R S_{16}$ & 331.51 & $R S_{27}$ & 316.73 & $R S_{38}$ & 356.22 \\
\hline$R S_{6}$ & 342.06 & $R S_{17}$ & 343.72 & $R S_{28}$ & 330.11 & $R S_{39}$ & 365.22 \\
\hline$R S_{7}$ & 349.99 & $R S_{18}$ & 350.07 & $R S_{29}$ & 337.2 & $R S_{40}$ & 363.09 \\
\hline$R S_{8}$ & 359.44 & $R S_{19}$ & 359.58 & $R S_{30}$ & 347.12 & $R S_{41}$ & 0 \\
\hline$R S_{9}$ & 357.3 & $R S_{20}$ & 358.28 & $R S_{31}$ & 345.83 & $R S_{42}$ & 347.22 \\
\hline$R S_{10}$ & 354.52 & $R S_{21}$ & 356.37 & $R S_{32}$ & 342.35 & $R S_{43}$ & 360.55 \\
\hline$R S_{11}$ & 353.01 & $R S_{22}$ & 354.71 & $R S_{33}$ & 340.02 & & \\
\hline \multicolumn{8}{|c|}{ ECOTI Score } \\
\hline$R S s$ & Jano-cataly & $R S s$ & Temp. & $R S s$ & Time & $R S s$ & MR \\
\hline$R S_{1}$ & 0.0000 & $R S_{12}$ & 0 & $R S_{23}$ & .0000 & $R S_{34}$ & 357.51 \\
\hline$R S_{2}$ & 305.78 & $R S_{13}$ & 307.82 & $R S_{24}$ & 294.79 & $R S_{35}$ & 367.57 \\
\hline$R S_{3}$ & 312.68 & $R S_{14}$ & 316.63 & $R S_{25}$ & 302.82 & $R S_{36}$ & 360.97 \\
\hline$R S_{4}$ & 320.15 & $R S_{15}$ & 324.5 & $R S_{26}$ & 310.44 & $R S_{37}$ & 360.13 \\
\hline$R S_{5}$ & 327.78 & $R S_{16}$ & 331.51 & $R S_{27}$ & 316.68 & $R S_{38}$ & 357.70 \\
\hline$R S_{6}$ & 341.97 & $R S_{17}$ & 343.71 & $R S_{28}$ & 330.03 & $R S_{39}$ & 364.36 \\
\hline$R S_{7}$ & 350.00 & $R S_{18}$ & 350.09 & $R S_{29}$ & 337.19 & $R S_{40}$ & 364.09 \\
\hline$R S_{8}$ & .44 & $R S_{19}$ & 359.58 & $R S_{30}$ & 347.12 & $R S_{41}$ & 0.0000 \\
\hline$R S_{9}$ & 356.95 & $R S_{20}$ & 358.13 & $R S_{31}$ & 345.08 & $R S_{42}$ & 346.96 \\
\hline$R S_{10}$ & 354.29 & $R S_{21}$ & 356.35 & $R S_{32}$ & 341.61 & $R S_{43}$ & 359.86 \\
\hline$R S_{11}$ & 352.79 & $R S_{22}$ & 354.67 & $R S_{33}$ & 339.11 & & \\
\hline
\end{tabular}




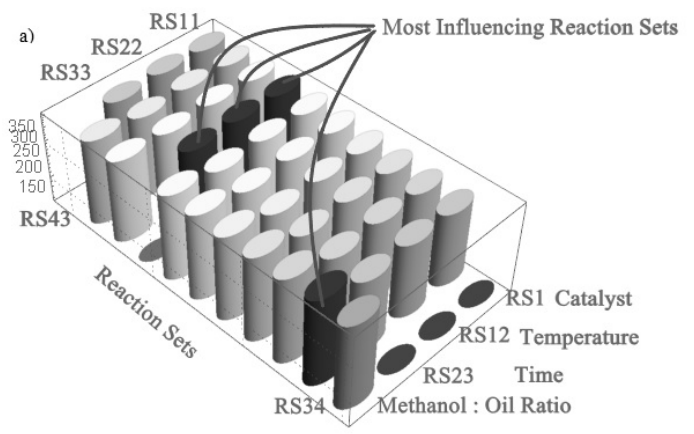

b)
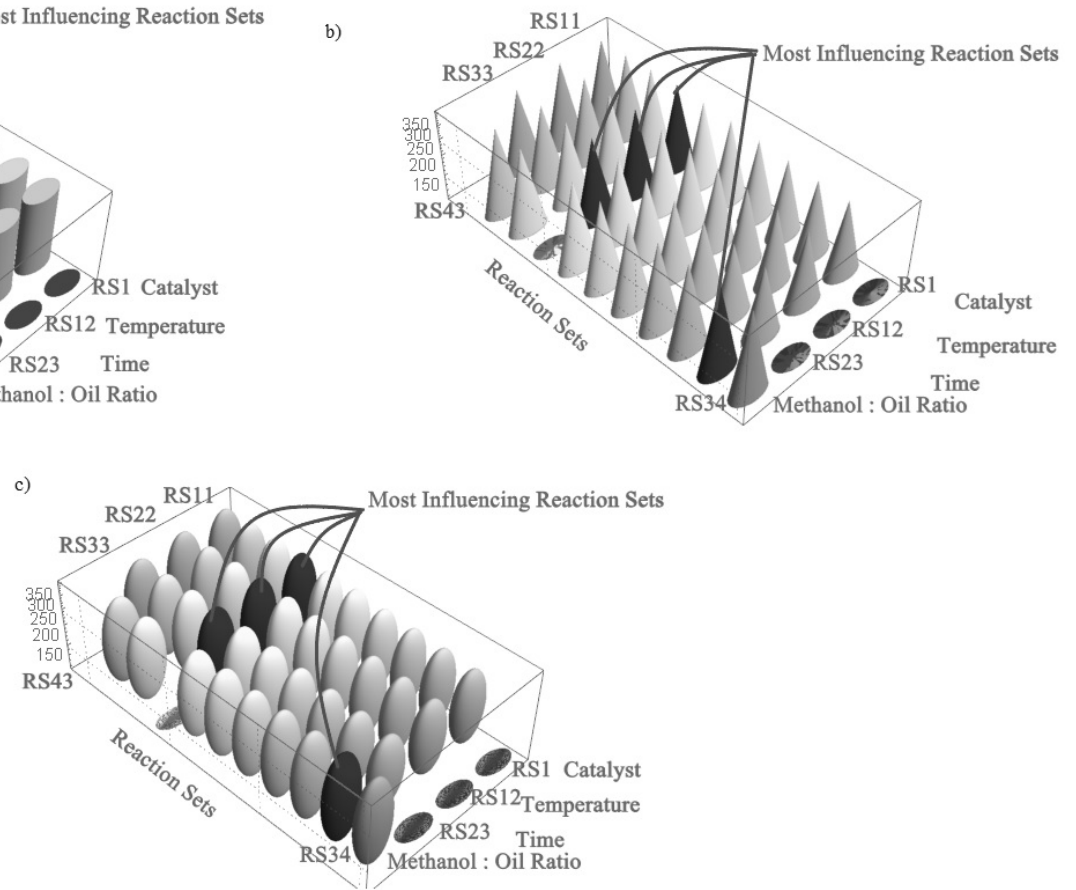

FIG. 5. Identification of Most Influencing Reaction Sets Employing a) ECOTI; b) FCOTI; c) SCOTI

\section{Conclusion}

This study investigates the synthesis of biodiesel using bio-synthesized nano-CaO as a nano-catalyst and employs a novel trigonometric fuzzy and SVNE-based methodology for evaluating the impact of various influencing factors (i) methanol/oil ratio (ii) concentration of nano-catalyst (iii) temperature and (iv) time of reaction on the biodiesel yield obtained through a heterogeneous nano-catalyst-based transesterification reaction. The proposed trigonometric entropy measures are deployed for constructing fuzzy entropy weighted waste cooking oil transesterification index (FCOTI) and SVNE weighted waste cooking oil transesterification index (SCOTI) respectively. The maximum FCOTI or SCOTI score concerning each influencing factor at various reaction sets indicated that the optimum methanol: oil ratio under the variation of nano-catalyst concentration from $0.5-2 \%$ and the temperature variation from $50-65{ }^{\circ} \mathrm{C}$ comes out to be 11:1 to provide the maximum yield of biodiesel. Further, out of the next three parameters, the effect of temperature is more prominent to obtain the best yield of biodiesel followed by nano-catalyst and time of reaction. If nano-catalyst and time are suitably controlled within the range of optimum values, the reaction temperature doesn't significantly affect the reaction yield. The classification of various influencing factors obtained through the proposed FCOTI and SCOTI coincides with the existing Deluca and Termini fuzzy entropy-based weighted waste cooking oil transesterification index (ECOTI). This confirms that the optimum parameters are nano-catalyst concentration value of $1 \%$, reaction temperature as $60^{\circ} \mathrm{C}$, methanol: oil ratio as $11: 1$, and reaction time as $4.5 \mathrm{hrs}$.

\section{References}

[1] Sodhi A.K., Tripathi S., Kundu K. Biodiesel production using waste cooking oil: a waste to energy conversion strategy. Clean Technologies and Environmental Policy, 2017, 19 (6), P. 1799-1807.

[2] Caliskan H., Mori K. Thermodynamic, environmental and economic effects of diesel and biodiesel fuels on exhaust emissions and nanoparticles of a diesel engine. Transportation Research Part D: Transport and Environment, 2017, 56, P. $203-221$.

[3] Yesilyurt M.K. A detailed investigation on the performance, combustion, and exhaust emission characteristics of a diesel engine running on the blend of diesel fuel, biodiesel and 1-heptanol (C7 alcohol) as a next-generation higher alcohol. Fuel, $2020,275,117893$.

[4] Alagh Y.K. India 2020. J. of Quantitative Economics, 2006, 4 (1), P. 1-14.

[5] Lam M.K., Lee K.T., Mohamed A.R. Homogeneous, heterogeneous and enzymatic catalysis for transesterification of high free fatty acid oil (waste cooking oil) to biodiesel: A review. Biotechnology Advances, 2010, 28 (4), P. 500-518.

[6] Martínez A., Mijangos G.E., et al. A novel green one-pot synthesis of biodiesel from Ricinus communis seeds by basic heterogeneous catalysis. J. of Cleaner Production, 2018, 196, P. 340-349.

[7] Udo G.J., Etesin U.M., et al. GCMS and FTIR Spectroscopy Characterization of Luffa Cylindrica Seed Oil and Biodiesel Produced from the oil. Communication in Physical Sciences, 2020, 5 (3), P. 378-390. 
[8] Fangsuwannarak K., Wanriko P., Fangsuwannarak T. Effect of Bio-polymer Additive on the Fuel Properties of Palm Biodiesel and on Engine Performance Analysis and Exhaust Emission. In: Energy Procedia, 2016, 100, P. 227-236.

[9] Ogunkunle O., Ahmed N.A. A review of global current scenario of biodiesel adoption and combustion in vehicular diesel engines. Energy Reports, 2019, 5 , P. 1560-1579.

[10] Ihoeghian N.A., Usman M.A. Exergetic evaluation of biodiesel production from rice bran oil using heterogeneous catalyst. J. of King Saud University - Engineering Sciences, 2020, 32 (2), P. 101-107.

[11] Mohd Noor C.W., Noor M.M., Mamat R. Biodiesel as alternative fuel for marine diesel engine applications: A review. Renewable and Sustainable Energy Reviews, 2018, 94, P. 127-142.

[12] Degirmenbasi N., Coskun S., Boz N., Kalyon D.M. Biodiesel synthesis from canola oil via heterogeneous catalysis using functionalized CaO nanoparticles. Fuel, 2015, 153, P. 620-627.

[13] Marwaha A., Rosha P., et al. Biodiesel production from Terminalia bellerica using eggshell-based green catalyst: An optimization study with response surface methodology. Energy Reports, 2019, 5 , P. 1580-1588.

[14] Ayoola A.A., Fayomi O.S.I., et al. Impact assessment of biodiesel production using CaO catalyst obtained from two different sources. Cogent Engineering, 2019, 6 (1), 1615198.

[15] Degfie T.A., Mamo T.T., Mekonnen Y.S. Optimized Biodiesel Production from Waste Cooking Oil (WCO) using Calcium Oxide (CaO) Nano-catalyst. Scientific Reports, 2019, 9 (1), 18982.

[16] Mansir N., Teo S.H., et al. Modified waste egg shell derived bifunctional catalyst for biodiesel production from high FFA waste cooking oil. A review. Renewable and Sustainable Energy Reviews, 2018, 82, P. 3645-3655.

[17] Wei Y., Zhang J., Zhang M., Zhang Y.D. Analysis on Factors Affecting Biodiesel Production Rate Based on Probability Theory. Advanced Materials Research, 2013, 860-863, P. 1030-1034.

[18] Zadeh L.A. Fuzzy sets. Information and control, 1965, 8 , P. 338-353.

[19] Ovchinnikov S. An Introduction to Fuzzy Relations. In: Fundamentals of Fuzzy Sets. 2015, P. $233-243$.

[20] Smarandache F.A. Unifying Field In Logics: Neutrosophic Logic. Neutrosophy, Neutrosophic Set, Neutrosophic Probability, American Research Press, Rehoboth, 2000.

[21] Tshizanga N., Aransiola E.F., Oyekola O. Optimisation of biodiesel production from waste vegetable oil and eggshell ash. South African Journal of Chemical Engineering, 2017, 23 , P. 145-156.

[22] Santya G., Maheswaran T., Yee K.F. Optimization of biodiesel production from high free fatty acid river catfish oil (Pangasius hypothalamus) and waste cooking oil catalyzed by waste chicken egg shells derived catalyst. SN Applied Sciences, 2019, 1 (2), P. 1-9.

[23] De Luca A., Termini S. A definition of a nonprobabilistic entropy in the setting of fuzzy sets theory. Information and Control, 1972, 20 (4), P. 301-312.

[24] Wei Z., Xu C., Li B. Application of waste eggshell as low-cost solid catalyst for biodiesel production. Bioresource Technology, 2009 , 100 (11), P. 2883-2885.

[25] Fayyazi E., Ghobadian B., et al. Optimization of Biodiesel Production over Chicken Eggshell-Derived CaO Catalyst in a Continuous Centrifugal Contactor Separator. Industrial \& Engineering Chemistry Research, 2018, 57 (38), P. 12742-12755.

[26] Borah M.J., Das A., et al. Transesterification of waste cooking oil for biodiesel production catalyzed by Zn substituted waste egg shell derived $\mathrm{CaO}$ nanocatalyst. Fuel, 2019, 242, P. 345-354.

[27] Ngadi N., Sulaiman S., Abd Rahman R., Lani N.S. Production of biodiesel from palm oil using cockle shell waste as heterogeneous catalyst. Jurnal Teknologi, 2017, 79 (5), P. 183-188.

[28] Purandaradas A., Silambarasan T., et al. Development and quantification of biodiesel production from chicken feather meal as a cost-effective feedstock by using green technology. Biochemistry and Biophysics Reports, 2018, 14, P. 133-139.

[29] Meena Devi R., Subadevi R., Paul Raj S., Sivakumar M. Comparative Studies on Biodiesel From Rubber Seed Oil Using Homogeneous and Heterogeneous Catalysts. Int. J. of Green Energy, 2015, 12 (12), P. 1215-1221.

[30] Brito G.M., Chicon M.B., et al. Eco-green biodiesel production from domestic waste cooking oil by transesterification using LiOH into basic catalysts mixtures. J. of Renewable and Sustainable Energy, 2020, 12 (4), 043101.

[31] Mumtaz M.W., Adnan A., et al. Response Surface Methodology: An Emphatic Tool for Optimized Biodiesel Production Using Rice Bran and Sunflower Oils. Energies, 2012, 5 (9), P. 3307-3328.

[32] Rabelo S.N., Ferraz V.P., Oliveira L.S., Franca A.S. FTIR Analysis for Quantification of Fatty Acid Methyl Esters in Biodiesel Produced by Microwave-Assisted Transesterification. Int. J. of Environmental Science and Development, 2015, 6 (12), P. 964-969.

[33] Touqeer T., Mumtaz M.W., et al. $\mathrm{Fe}_{3} \mathrm{O}_{4}$-PDA-Lipase as Surface Functionalized Nano Biocatalyst for the Production of Biodiesel Using Waste Cooking Oil as Feedstock: Characterization and Process Optimization. Energies, 2019, 13 (1), 177.

[34] Hangun-Balkir Y. Green Biodiesel Synthesis Using Waste Shells as Sustainable Catalysts with Camelina sativa Oil. J. of Chemistry, 2016, 2016, P. $1-10$ 